\title{
Hubungan Karakteristik Ibu dan Jarak Pelayanan Kesehatan Dengan Kelengkapan Imunisasi Dasar di Puskesmas Dulukapa
}

\section{Elvi Libunelo'), Yeni Paramata2) dan Rahmawati3)}

\begin{abstract}
1I lmu Kesehatan Masyarakat, Fakultas Kesehatan Masyarakat Universitas Gorontalo email: elvilibunelo81@gmail.com

2I lmu Kesehatan Masyarakat, Fakultas Kesehatan Masyarakat Universitas Gorontalo email: yeniparamata20@gmail.com 3I lmu Kesehatan Masyarakat, Fakultas Kesehatan Masyarakat Universitas Gorontalo email: rahma.amma9720@gmail.com
\end{abstract}

\begin{abstract}
Every year more than 1.4 million children in the world die from various diseases that can be prevented by immunization. The purpose of this research was to know the relationship of mother characteristic and distance of health service to the completeness of basic immunization in infant in Dulukapa.The type of the study was an analytic survey using cross sectional study design, sampling technique ie exhautive sampling which was a sampling scheme where the researcher token all the subjects from the population as the samples as many as 150 babies. The analysis was used univariate and bivariate analysis with chi square test. The proportion of infants who received complete immunization 92 (61.3\%) infants and immunizations did not complete as many as 58 (38.7\%) babies. Using the chi square statistical test showed that there was significant associated between maternal education ( $p$ value $=0.002)$, maternal occupation $(p$ value $=0,000)$, maternal $k$ nowledge $(p$ value $=0,000)$, health service distance $(p$ value $=0,002)$ with completeness of immunization base on the baby. To improve the completeness of basic immunization in infants, the mother should pay attention to infant health and always bring the baby to the immunization and to the health center and health personnel to further improve health education routinely, especially in the provision of basic immunization.
\end{abstract}

Keywords : Immunization, Education, Knowledge, Occupation

\section{PENDAHULUAN}

Setiap tahun lebih dari 1,4 juta anak di dunia meninggal karena berbagai penyakit yang sebenarnya dapat dicegah dengan imunisasi. Imunisasi adalah suatu upaya untuk menimbulkan/meningkatkan kekebalan seseorang secara aktif terhadap suatu penyakit, sehingga bila suatu saat terpapar dengan penyakit tersebut tidak akan sakit atau hanya mengalami sakit ringan. Anak 
yang telah diberi imunisasi akan terlindungi dari berbagai penyakit berbahaya yang dapat menimbulkan kecacatan atau kematian (Kemenkes RI, 2015).

Imunisasi diperkirakan 2 hingga 3 juta kematian setiap tahun dari penyakit Difteri, Tetanus, Pertusis (batuk rejan), dan Campak. Namun, tambahan 1,5 juta kematian dapat dihindari jika cakupan vaksinasi global membaik. Proporsi cakupan vaksinasi anak di dunia yang menerima vaksin direkomendasikan tetap stabil selama beberapa tahun terakhir. Selama tahun 2015, sekitar 86\% (116 juta) dari bayi di seluruh dunia menerima 3 dosis Difteri-Tetanus-Pertusis (DTP3) vaksin untuk melindungi mereka terhadap penyakit menular yang dapat menyebabkan penyakit serius dan cacat atau berakibat fatal. Pada tahun 2015, 126 negara telah mencapai cakupan minimal 90\% dari vaksin DTP3 (WHO, 2016).

Berdasarkan data yang dilansir oleh Kemenkes RI, cakupan Imunisasi Dasar Lengkap (IDL) masih mencapai angka 86,8\% pada April 2015. Pada tahun 2019, Kemenkes menargetkan cakupan imunisasi perlu ditingkatkan hingga mencapai target 93\%. Fakta di lapangan menunjukkan bahwa masih ada kelompok masyarakat yang belum terjangkau oleh pelayanan kesehatan (UNAIR, 2016).

Berdasarkan data Dinas kesehatan Provinsi Gorontalo cakupan IDL pada tahun 2014 yakni mencapai 88,9\%, pada tahun 2015 mencapai 80,7\%, pada tahun 2016 mencapai 71,1\%. Hal ini menunjukan bahwa dalam waktu 3 tahun terjadi penurunan cakupan imunisasi. Dilihat menurut Kabupaten dan Kota, pada tahun 2014 cakupan imunisasi terendah berada pada Kabupaten Gorontalo sebesar 77,9\% dan cakupan imunisasi tertinggi di Kabupaten Pohuwato sebesar $106,7 \%$. Sedangkan pada tahun 2015 cakupan imunisasi terendah pada Kabupaten Bone Bolango sebesar 72,3\% dan cakupan imunisasi tertinggi pada Kabupaten Boalemo sebesar 93.0\%. Pada tahun 2016 cakupan imunisasi terendah yaitu pada Kabupaten Gorontalo Utara sebesar 47,2\% dan cakupan imunisasi tertinggi pada Kota Gorontalo sebesar 96,0\% (Dinkes Provinsi Gorontalo, 2016).

Berdasarkan data dari Puskesmas Dulukapa pada tahun 2015 dari 111 bayi hanya ada 103 bayi atau sebesar 92,8\% bayi yang melakukan imunisasi dasar lengkap. Pada tahun 2016 dari 150 jumlah bayi hanya ada 92 bayi $(61,3 \%)$ yang melakukan imunisasi dasar lengkap dan $58(38,7 \%)$ bayi yang tidak melakukan imunisasi dasar lengkap (Puskesmas Dulukapa, 2016). Hasil tersebut menunjukan bahwa pemberian imunisasi dasar lengkap belum memenuhi target Kemenkes RI yaitu sebesar 93\%. Tujuan penelitian untuk mengetahui hubungan karakteristik ibu dan jarak pelayanan kesehatan terhadap kelengkapan imunisasi dasar pada bayi di Puskesmas Dulukapa Kabupaten Gorontalo Utara.

\section{METODE PENELITIAN}

Jenis penelitian yang digunakan adalah Jenis penelitian survey analitik dengan menggunakan rancangan cross sectional study. Lokasi penelitian dilakukan di wilayah kerja Puskesmas Dulukapa Kabupaten Gorontalo Utara pada bulan Maret sampai bulan April 2017. Populasi dalam penelitian ini adalah seluruh bayi yang berumur 9-12 bulan yang mendapat imunisasi dasar lengkap ataupun yang tidak mendapat imunisasi dasar lengkap dengan jumlah 150 bayi. Teknik pengambilan sampel yang digunakan adalah exhaustive sampling dimana peneliti mengambil semua subjek dari populasi sebagai sampel untuk diteliti dengan kriteria tertentu (Notoatmodjo, 2005). 
Data yang dikumpulkan adalah data primer dan data sekunder, data primer diperoleh melalui wawancara langsung dengan menggunakan kuesioner, sedangkan data sekunder diperoleh melalui laporan dinas Kesehatan dan Puskesmas Dulukapa. Pengolahan data dilakukan menggunakan komputer dengan program Statistical Package For The Sciences (SPSS) yang disajikan dalam bentuk tabel kemudian dinarasikan dan analisis yang digunakan yaitu univariat dan bivariat dengan uji Chi Square untuk melihat hubungan antara variabel dependen dengan variabel independen.

\section{HASIL DAN PEMBAHASAN}

3.1 Analisis Karakteristik Subjek Penelitian

Tabel 1. Karakteristik Responden

\begin{tabular}{ccc}
\hline Variabel & $\mathrm{n}$ & $\%$ \\
\hline Kelompok Umur (Tahun) & 7 & \\
$16-20$ & 52 & 4,7 \\
$21-25$ & 59 & 34,7 \\
$26-30$ & 21 & 39,3 \\
$31-35$ & 6 & 56,2 \\
$36-40$ & 5 & 14,0 \\
$>40$ & 77 & 3,3 \\
Tingkat Pendidikan & 53 & 51,3 \\
SD & 16 & 35,3 \\
SMP & 4 & 10,6 \\
SMA & & 2,7 \\
Perguruan Tinggi & 83 & 55,3 \\
Pekerjaan & 4 & 2,7 \\
IRT & 63 & 42 \\
PNS & & \\
Wiraswasta & 94 & 62,7 \\
Tingkat Pengetahuan & 56 & 37,3 \\
Cukup & & 68,0 \\
Kurang & 102 & 32,0 \\
Jarak pelayanan & 48 & \\
Terjangkau & & \\
Tidak Terjangkau &
\end{tabular}

Berdasarkan tabel 1 tersebut terlihat bahwa umur yang lebih banyak terdistribusi pada umur 26-30 tahun yaitu sebanyak 59 respoden $(39,3 \%)$ dan yang terendah terdapat pada umur $>40$ tahun yaitu sebanyak 5 responden $(3,3 \%)$. Untuk pendidikan dapat dilihat bahwa tingkat pendidikan yang lebih banyak terdistribusi yaitu pendidikan SD sebanyak $77(51,3 \%)$ responden dan tingkat pendidikan terendah terdapat pada perguruan tinggi sebanyak 4 responden $(2,7 \%)$. Untuk pekerjaan dapat dilihat bahwa distribusi responden berdasarkan pekerjaan sampel tertinggi terdapat pada responden yang bekerja sebangai Ibu rumah tangga yaitu sebanyak $83(55,3 \%)$ responden dan yang terendah terdapat pada responden yang bekerja sebagai PNS yaitu sebanyak 4 responden $(2,7 \%)$. Untuk tingkat pengetahuan dapat dilihat bahwa yang lebih banyak terdistribusi pada tingkat pengetahuan cukup yaitu 
sebanyak 94 responden (62,7\%). Untuk jarak pelayanan kesehatan dapat dilihat bahwa yang lebih banyak terdistribusi pada jarak yang terjangkau yaitu sebanyak 102 responden $(68,0 \%)$.

\subsection{Analisis Karakteristik dan Jarak Pelayanan Kesehatan terhadap Kelengkapan Imunisasi Dasar}

Tabel 2. Analisis Pendidikan, Pekerjaan, Pengetahuan Dan Jarak Pelayanan Dengan Kelengkapan Imunisasi Dasar

\begin{tabular}{|c|c|c|c|c|c|c|c|}
\hline \multirow{3}{*}{ Variabel } & \multicolumn{4}{|c|}{$\begin{array}{c}\text { Kelengkapan Imunisasi } \\
\text { Dasar }\end{array}$} & \multirow{2}{*}{\multicolumn{2}{|c|}{ Total }} & \multirow{3}{*}{$\begin{array}{c}X^{2} \\
\rho \text { value }\end{array}$} \\
\hline & \multicolumn{2}{|c|}{$\begin{array}{c}\text { Tidak } \\
\text { Lengkap }\end{array}$} & \multicolumn{2}{|c|}{ Lengkap } & & & \\
\hline & $\mathrm{n}$ & $\%$ & $\mathrm{n}$ & $\%$ & $\mathrm{n}$ & $\%$ & \\
\hline \multicolumn{8}{|l|}{ Pendidikan } \\
\hline Tinggi & 19 & 26,0 & 54 & 74,0 & 73 & 100 & 9,579 \\
\hline Rendah & 39 & 50,0 & 38 & 49,4 & 77 & 100 & 0,002 \\
\hline \multicolumn{8}{|l|}{ Pekerjaan } \\
\hline Bekerja & 15 & 22,4 & 52 & 77,6 & 67 & 100 & 13,530 \\
\hline Tidak Bekerja & 43 & 51,8 & 40 & 48,2 & 83 & 100 & 0,000 \\
\hline \multicolumn{8}{|l|}{ Pengetahuan } \\
\hline Cukup & 27 & 28,7 & 67 & 71,3 & 94 & 100 & 10,497 \\
\hline Kurang & 31 & 55,4 & 25 & 44,6 & 56 & 100 & 0,001 \\
\hline \multicolumn{8}{|l|}{ Jarak Pelayanan } \\
\hline Terjangkau & 31 & 30,4 & 71 & 69,6 & 102 & 100 & 9,202 \\
\hline Tidak & 27 & 56,2 & 21 & 43,8 & 48 & 100 & 0,002 \\
\hline
\end{tabular}

Berdasarkan tabel 2 dengan menggunakan hasil uji statistik Chi Square menunjukan Ada hubungan pendidikan ibu ( $p$ Value $=0,002<\mathrm{a} 0,05)$, pekerjaan ibu ( $p$ Value $=0,000<\mathrm{a} 0,05)$, pengetahuan ibu dengan $(p$ Value $=0,000<\mathrm{a} 0,05)$, dan jarak pelayanan kesehatan ( $p$ Value $=0,002<\mathrm{a} 0,05)$ dengan kelengkapan imunisasi dasar pada bayi di Wilayah Kerja Puskesmas Dulukapa Kabupaten Gorontalo Utara tahun 2016.

Tingkat pendidikan merupakan jenjang pendidikan terakhir yang ditempuh seseorang. Tingkat pendidikan merupakan suatu wahana untuk mendasari seseorang berperilaku secara ilmiah (Irianto, 2014). Tingkat pendididkan ibu sangat menentukan kemudahan dalam menerima setiap pembaharuan. Makin tinggi tingkat pendidikan ibu, maka akan semakin cepat tanggap dengan perubahan kondisi lingkungan, dengan demikian lebih cepat menyesuaikan diri dan selanjutnya akan mengikuti perubahan itu (Notoatmodjo, 2003). Berdasarkan hasil analisis statistik dengan menggunakan uji chi square terdapat hubungan antara tingkat pendidikan ibu dengan kelengkapan imunisasi dasar pada bayi di wilayah kerja Puskesmas Dulukapa ( $p$ Value $<0,05$ ).Penelitian ini sejalan dengan yang dilakukan oleh Mulyanti bahwa hasil uji statistik diperoleh nilai $p$ Value $=0,04<0,05$ dengan nilai $\mathrm{OR}=36,153$ yang berarti bahwa ada hubungan yang signifikan antara tingkat pendidikan terhadap kelengkapan imunisasi (Mulyanti, 2013). Penelitian ini tidak sejalan dengan yang dilakukan Vivi Triana di kecamatan Kuranji kota Padang bahwa diperoleh nilai $p=0,34$ karena nilai $p>0,05$ artinya tidak terdapat hubungan yang bermakna antara 
tingkat pendidikan ibu dengan kepatuhan ibu dalam pemberian imunisasi dasar pada balita (Triana, 2016).

Pekerjaan adalah barang apa yang dilakukan, diperbuat atau dikerjakan seseorang (Depdikbud, 2006). Ibu bekerja mempunyai kesempatan meluangkan waktu secara maksimal pada hari-hari libur, dimana pada hari itu peluang dan kesempatan ibu untuk mengurus kesehatan anak adalah besar. Misalnya pergi ke tempat pelayanan kesehatan yang buka pada hari itu khususnya praktek dokter dan bidan swasta (Khalimah, 2007). Berdasarkan hasil analisis statistik dengan menggunakan uji chi square, terdapat hubungan antara tingkat pekerjaan ibu dengan kelengkapan imunisasi dasar pada bayi di wilayah kerja Puskesmas Dulukapa (pValue < 0,05). Penelitian ini sejalan dengan yang dilakukan oleh Nugroho di Desa Japanan Kecamatan Cawas Kabupaten Klaten menyatakan bahwa ada hubungan antara tingkat pekerjaan ibu dengan kelengkapan status imunisasi dasar bayi berdasarkan uji chi-square diperoleh nilai $p=0,002$ (Nugroho, 2013). Penelitian ini tidak sejalan dengan yang dilakukan oleh Vivi Triana mengenai faktor yang berhubungan dengan pemberian imunisasi dasar lengkap pada bayi tahun 2015 menunjukkan bahwa tidak terdapat hubungan yang bermakna antara pekerjaan dengan status imunisasi diperoleh nilai $p=0,66$ (Triana, 2016).

Pengetahuan selain dari informasi dapat juga diperoleh dari pengalaman seseorang yang pernah terjadi pada masa lalu atau pada masa sekarang. Pengalaman adalah guru terbaik yang merupakan sumber pengetahuan dan informasi yang dapat dipahami dan dimengerti oleh individu itu sendiri dari proses belajar yang sudah dilakukannnya. Informasi juga dapat mempengaruhi pengetahuan ibu tentang imunisasi. Pada jaman modern ini informasi dapat diperoleh dari berbagai media, misalnya media cetak maupun elektronik. Misalnya iklan di televisi yang menayangkan PIN, secara tidak langsung iklan tersebut mengingatkan tentang pentingnya imunisasi (Nugroho, 2013). Berdasarkan hasil analisis statistik dengan menggunakan uji chi square terdapat hubungan antara tingkat pengetahuan ibu dengan kelengkapan imunisasi dasar pada bayi di wilayah kerja Puskesmas Dulukapa ( $p$ Value $<0,05$ ). Penelitian ini sejalan dengan penelitian yang dilakukan oleh Emir Gahara, dkk di Puskesmas Kampung Sawah yang menyatakan bahwa ada hubungan antara pengetahuan ibu dengan kelengkapan status imunisasi dasar bayi berdasarkan uji chi-square diperoleh nilai $p=0.002$ (Gahara et al., 2015). Penelitian ini tidak sejalan dengan penelitian yang dilakukan Tri Afriani, dkk di Puskesmas dan Posyandu Kecamatan X Kota Depok, diperoleh nilai $p=0.062$, karena nilai $p>0.05$ yang artinya tidak terdapat hubungan yang bermakna antara pengetahuan ibu dengan pemberian imunisasi dasar pada anak (Afriani, Dkk, 2013).

Jarak adalah ruang sela (panjang atau jauh) antara dua benda atau dua tempat. Jarak dekat adalah ruang sela yang pendek antara dua benda atau tempat. Jarak jauh adalah ruang sela yang panjang antara dua tempat dan sebagainya (KBBI, 2013). Berdasarkan hasil analisis statistik dengan menggunakan uji chi square terdapat hubungan antara jarak pelayanan kesehatan dengan kelengkapan imunisasi dasar pada bayi di wilayah kerja Puskesmas Dulukapa ( $p$ Value < 0,05). Penelitian ini sejalan dengan penelitian Mulyanti dengan judul analisis hubungan antara jarak rumah ke pelayanan imunisasi dengan kelengkapan imunisasi dasar pada balita 1-5 tahun di wilayah kerja Puskesmas Situgintung Ciputat bahwa berdasarkan hasil analisis dengan 
Libunelo, dkk

uji statistik diperoleh $p$ value $=0,000$ dengan tingkat kepercayaan $95 \%$ dengan nilai $\mathrm{OR}=18.857$ ( $p$ Value $<0.05)$ (Mulyanti, 2013). Penelitian ini tidak sejalan dengan penelitian yang dilakukan Endah Ningrum dan Sulastri di Puskesmas Banyudono Kabupaten Boyolali, diperoleh nilai $p=0.263$, karena nilai $p>0.05$ yang artinya tidak mempunyai pengaruh signifikan terhadap kelengkapan imunisasi dasar (Ningrum dan Sulastri, 2013).

Variabel jarak dikatakan ada hubungan dengan kelengkapan imunisasi dasar pada bayi dikarenakan berdasarkan penelitian ibu yang memiliki jarak tempat pelayanan terjangkau lebih banyak diimunisasi lengkap di bandingkan dengan ibu yang memiliki jarak yang tidak terjangkau, dimana semakin jauh jarak yang ditempuh untuk melakukan imunisasi maka semakin tidak lengkap imunisasi pada bayi sebab ibu yang jarak rumahnya terlalu jauh dengan tempat pelayanan imunisasi akan berfikir kesekian kali untuk datang ke tempat pelayanan. Sebab sebagian ibu berpendapat bahwa daripada mengeluarkan biaya ke tempat imunisasi lebih baik uang tersebut dipakai untuk kebutuhan sehari-hari, begitu pula sebaliknya untuk pergi ke tempat dengan cara berjalan kaki menurut mereka akan menghabiskan waktu, lebih baik waktu tersebut dimanfaatkan untuk pekerjaan lain, misalnya mengurus pekerjaan rumah.

\section{KESIMPULAN DAN SARAN}

Berdasarkan hasil penelitian dapat disimpulkan bahwa ada hubungan antara pendidikan, pekerjaan, pengetahuan dan jarak pelayanan kesehatan dengan kelengkapan imunisasi dasar pada bayi di wilayah kerja Puskesmas Dulukapa Kabupaten Gorontalo Utara tahun 2016. Bagi ibu diharapkan agar selalu membawa bayinya untuk dimunisasi dan kepada tenaga kesehatan agar lebih meningkatkan penyuluhan tentang kesehatan secara rutin khususnya dalam pemberian imunisasi dasar serta bagi peneliti perlu penelitian lanjut guna untuk menilai variabel-variabel yang belum di teliti,sehingga nantinya dapat mengungkapkan berbagai hal yang dapat mempengaruhi kelengkapan imunisasi dasar pada bayi.

\section{REFERENSI}

Afriani T, Andrajati R dan Supardi S. 2013. Faktor-faktor yang berhubungan dengan kelengkapan imunisasi dasar pada anak dan pengelolaan vaksin di puskesmas dan posyandu kecamatan X kota Depok. Buletin Penelitian Sistem Kesehatan. Vol.17 No.2 April 2014: 135-142.

Depdikbud. 2006. Kamus Besar Bahasa Indonesia. Balai Pustaka: Jakarta.

Dinas Kesehatan Provinsi Gorontalo. 2014-2015. Data Cakupan Imunisasi. Gorontalo.

Gahara E, Saftarina F, Lisiswanti R, Dewiarti Nusa A. 2015. Hubungan Tingkat Pengetahuan Ibu Dan Status Ekonomi Dengan Kelengkapan Imunisasi Wajib Pada Anak Usia 0-12 Bulan di Puskesmas Kampung Sawah. Majority. Vol.4 No.9, Desember 2015,144.

Irianto. 2014.Gizi Seimbang Dalam Kesehatan Reproduksi (Balanced Nutrition In Reproductive Health). Alfabeta: Bandung

Kemenkes RI, 2015. Profil Kesehatan Indonesia Tahun 2014. Kementerian kesehatan RI Jakarta Indonesia.

Khalimah U. 2007. Hubungan antara Karakteristik dan Sikap Ibu Batita dengan Penerapan Imunisasi Campak di Wilayah Kerja Puskesmas Sekaran 
Gunungpati Semarang. Skripsi. Jurusan Ilmu Kesehatan Masyarakat Fakultas Ilmu Keolahragaan Universitas Negeri Semarang.

Mulyanti Y. 2013. Faktor - Faktor Internal Yang Berhubungan Dengan Kelengkapan Imunisasi Dasar Balita Usia 1-5 Tahun Diwilayah Kerja Puskesmas Situ Gintung Ciputat Tahun 2013. Skripsi. Keperawatan Fakultas Kedokteran Dan Ilmu Kesehatan Universitas Islam Negeri Syarif Hidayatullah

Ningrum E dan Sulastri. 2013. Faktor-Faktor Yang Mempengaruhi Kelengkapan Imunisasi Dasar Pada Bayi di Puskesmas Banyudono Kabupaten Boyolali.Berita Ilmu Keperawatan. ISSN 1979-2697, Vol.1 No.1, Maret 2008: 7-12.

Notoatmodjo, S. 2005. Metodologi Penelitian Kesehatan. Rineka Cipta. Jakarta. . 2003. Pendidikan dan Perilaku Kesehatan. Rineka Cipta: Jakarta.

Nugroho P.J. 2013. Hubungan Tingkat Pengetahuan, Usia dan Pekerjaan Ibu dengan Status Imunisasi Dasar Bayi di Desa Japanan Kecamatan Cawas Kabupaten Klanten Tahun 2013. Skripsi. Fakultas Ilmu Kesehatan. Universitas Muhammadiyah Surakarta

Puskesmas Dulukapa. 2016. Data Cakupan Imunisasi tahun 2015-2016. Gorontalo Utara.

Triana, V, 2016. Faktor Yang Berhubungan Dengan Pemberian Imunisasi Dasar Lengkap Pada Bayi. Jurnal Kesehatan Masyarakat Andalas. Vol.10, No. 2 tahun 2016.

UNAIR. 2016. Tingkatkan Cakupan Imunisasi Indonesia. http://news.unair.ac.id/2016/03/08/tingkatkan-cakupan-imunisasiindonesia/. Diakses Tanggal 15 Januari 2017

WHO. 2016. World Immunization Coverage. http:/ /www.who.int.imediacentere/ factsheets/fs378/en/. Diakses Tanggal 15 Januari 2017 